\title{
Review of: "Calculating dissolved marine oxygen values based on an enhanced Benthic Foraminifera Oxygen Index"
}

\author{
Jitendra Pandey ${ }^{1}$ \\ 1 Banaras Hindu University
}

Potential competing interests: The author(s) declared that no potential competing interests exist.

\section{Review of: "Calculating Dissolved Marine Oxygen Values Based on an Enhanced Benthic Foraminifera Oxygen Index"}

\section{Jitendra Pandey}

Environmental Science Division, Department of Botany, Institute of Science, Banaras Hindu University, Varanasi-221005, India

Human-induced changes have triggered a shift in ocean chemistry leading to reduced concentration of dissolved oxygen (DO) in a large part of the world ocean. The areas with very low DO values often called as oxygen minimum zones (OMZs) are rapidly expanding throughout the world ocean leading to adverse effects on ocean metabolic cycle and severe reduction in ocean biodiversity especially the benthic macroand microorganisms. The hypoxic areas have expanded to over $2.45 \times 10^{5} \mathrm{~km}^{2}$ covering over 400 different areas worldwide (Diaz and Rosenberg, 2008). This embarked the reconstruction of marine oxygen status of recent and geological past. The foraminifers are among the most abundant single celled benthic protists present in deep sea fossil record. Being highly sensitive to environmental fluctuations (temperature, salinity, $\mathrm{pH}$, dissolved oxygen, food resources etc.), foraminifers are widely used for palaeoceanographic reconstructions (Tetard et al., 2021). By combining multiple proxies, Kranner et al. (2022) have developed Enhanced Benthic Foraminfera Oxygen Index (EBFOI) by modifying Kaiho's (Kaiho, 1994) original BFOI. Descriptive information on bottom water oxygen (BWO) based on samples from different depositional environment together with some measured DO ( $\mathrm{mDO}$ ) values have been used to validate EBFOI and new transfer function. The authors used correlative evidences to ascertain the magnitude of synchronization between the calculated DO (cDO) and mDO values. The resulting offset has been linked with the caveats associated with the distance of sampling locations and other causes of variability between mDO and CDO, especially to those related with the lack of PWO measurements.

Kranner's index merits attention contexting three major issues: The new calculations (this ref.) also consider transitional state- the sub-oxic indicators to remove constraints associated with considering samples with oxic- and lack of oxic indicators only. Furthermore, in addition to calcareous foraminifers, it also includes agglutinated genera. This large group, which account for about two-third of all foraminiferal genera in geographical record, inhabit the ocean floor below the calcium compensation depth. The findings 
have been compared/validated with seven recent datasets (references given in the original paper) together with additional fossil database of the Palaeocene, the Oligocene and the Miocene. Kranner et al. (2022) also considers bottom water oxygenation (BWO) and pore water oxygenation (PWO); and a transfer function for conversion of EBFOI directly to DO values with about 38\% greater efficiency. Lack of attention towards sub-oxic indicators has been identified as a major shortcoming/lack of effectiveness in Kaiho's original formula which considered the presence of oxic or no oxic indicators separately (no sub-oxic indicators included). This could lead to an over estimation of DO concentration, claims Kranner et al. (2022). These authors claim a value addition (enhanced effectiveness) to BFOI by adding three groups based on oxygen requirement of 417 foraminiferal species. They included oxic (DO $>1.5 \mathrm{ml} / \mathrm{l}$ ), sub-oxic (1.5-0.3 ml/l) and dys-oxic (0.3-0.1 ml/l) sub-groups to omit constraints associated with non-inclusion of transitional state.

This study has relevance in constructing DO values and predicting the expanding state of OMZs. However, it invites concerns questioning the effectiveness of EBFOI and its claims of improvement over the original calibration of Kaiho (1994). The major apprehension associated with the study is that how sensitively the sharp distinctions among species responding to oxic (DO $>1.5 \mathrm{ml} / \mathrm{l})$, sub-oxic $(1.5-0.3 \mathrm{ml} / \mathrm{l})$ and dys-oxic (0.3-0.1 ml/l) conditions have been investigated and how critically oxygen requirement has been addressed? The accuracy of prediction relies on precision of concurrence of foraminifers and oxygen requirement and also on the precision of combining PWO with BWO. Quantitatively, evaluating and predicting a very small range of oxygen tolerance, for instance, DO levels $1.5-0.3 \mathrm{ml} / \mathrm{l}$ and $0.3-0.1 \mathrm{ml} / \mathrm{l}$, is a difficult task. Because of the multiplicity of regulatory determinants of DO for in situ oxygen concentration data, the variances generally remain very high. Accordingly, the variances in foraminifer responses to transitional shifts in DO concentrations (vs tolerance) could be expected to be very high. Under such condition accurate assignment of oxygen requirement of benthic foraminifers as a reliable proxy of transitional shifts in DO will be difficult and a relatively wider range of oxygen sensitivity responses of foraminifers (vs tolerance) considered in Kaiho (1994) seems more reliable. Furthermore, the inconsistencies between calculated BFOI and oxygen trends in Kaiho (1994) as pointed out by Kranner et al. (2022) based on Austrian Vienna Basin could be linked with multiple transgression and regression events associated with temperature and other anomalies during the Miocene. Also, the agglutinated foraminifers might use remnants of pre-existing foraminifer's calcareous particles as their outer covering, and hence there inclusion here is unlikely to add a significant merit over Kaiho (1994).

\section{References}

Diaz, R. J. and Rosenberg, R. (2008) Spreading dead zones and consequences for marine ecosystems.

Science, 321: 926-929/

Kaiho, K. (1994) Benthic foraminiferal dissolved-oxygen index and dissolved-oxygen levels in the modern ocean. Geology, 22: 719-732.

Kranner, M., Harzhauser, M., Beer, C., Auer, G. and Piller, W. E. (2022) Calculating dissolved marine oxygen values based on an enhanced benthic foraminifera oxygen index. Scientific Reports, 12: 1376 
Tetard, M., Licari, L., Ovsepyan, E., Tachikawa, K. and Beaufort, L. (2021) Towards a global calibration for quantifying past oxygenation in oxygen minimum zones using benthic foraminifera. Biosciences, 18: $2827-$ 2841. 